\title{
Foreign report
}

\section{Changing practices in mental health care: a lesson from America}

\author{
Tom Butler, Care Group Manager; and Philip Thomas, Consultant Psychiatrist, \\ Department of Psychiatry, Rawnsley Building, Manchester Royal Infirmary, \\ Oxford Road, Manchester M13 9WL
}

Health and social care in Britain is undergoing the most profound changes in its structure and organisation since its inception (Griffiths, 1988); indeed, some would argue that it is about to change beyond recognition. The purpose of this article is to describe contemporary developments in the delivery of such services in the USA. Given that many of the political changes here have been directly influenced by thinking and practice in that country, it is argued that there are two important lessons to be learnt. The first concerns the coordination of service delivery between different agencies, the second involves an emphasis on the delivery of acute and rehabilitation services in the community. In short the traditional distinctions between the two would be blurred.

\section{The community mental health movement}

One of the most influential developments in America since the end of the last war has been the community mental health movement. Two main themes influenced its evolution. First, crisis theory and the work of Kaplan, which stressed the importance of brief therapeutic interventions for people in acute crisis. Second, the successful implementation of rapid assessment and management of soldiers suffering acute stress reactions in warfare. The introduction of phenothiazines in the 1950s as treatment for acute psychoses enabling patients to return rapidly to the community should have set the seal on a shift in emphasis from hospital to community care through the community mental health movement.

In America this resulted in major changes in the delivery of mental health services as well as who received them. Federal funding established over 700 community mental health centres (CMHCs) covering over half the population. Out-patient attendances increased from 1.5 million to almost 2.5 million over the 30 years between 1950 and 1980 . However, over the same period, the population of the State Hospitals fell dramatically from over 0.5 million to
0.12 million, a decrease of $75 \%$ (Goldman et al, 1983). But a simple cause-effect relationship between these observations cannot be assumed. As Goldman has observed (Goldman \& Morrissey, 1985), the huge increase in out-patient attendances was largely accounted for by a group of people not previously in receipt of psychiatric care, such as those in acute crisis, and those undergoing acute neurotic reactions, or as Goldman puts it "the worried well". What happened to the hundreds of thousands of long-stay patients formerly resident in the State Hospitals?

Federal funding for the CMHCs by-passed the State Hospitals but the legislation which established CMHCs did not require them to provide accommodation, nor any other of the basic needs of the discharged chronically mentally ill which the State Hospitals had previously provided. While the closure of the old State Hospitals may well have been right in terms of social policy, social justice and economics, they had at least provided the basic human needs of shelter, food,clothing, and recreation. As a result the chronically mentally ill (CMI) drifted into the centres of large cities. While by 1980 some 700,000 were in private nursing homes, some found their way into jail, and some became homeless. In certain areas the Greyhound Bus Company provided as much aftercare as psychiatric services, with chronic patients sent down inter-state highways to the State boundary where they became someone else's problem.

In essence the CMHCs had failed to accept any responsibility for the care of people with $\mathrm{CMI}$, whose chronic health problems were not an attractive proposition for the health insurance companies. Access to care and services became an accident of geography, and no mechanism existed for coordinating the after-care of these patients.

\section{Community mental health systems}

At the start of the 1980s it was apparent that there was a desperate need to reform the care of people suffering from CMI, and two organisations were 
pre-eminent in attempts to improve the delivery of health care. The federally funded National Institute of Mental Health (NIMH) started to support demonstration projects for those suffering from substance misuse. But perhaps most significant was the initiative taken by the Robert Wood Johnson Foundation (RWJF), a philanthropic charity founded by the Johnson \& Johnson Company. For many years, concerned with the plight of the homeless in the USA, they had considerable experience in providing funding for housing and related resources. Through working in this field they identified the CMI to be amongst those with some of the most severe housing problems.

The RWJF, through a joint initiative with the US Department of Housing and Urban Development (HUD), established a five-year project to develop a comprehensive system of mental health care. They invited applications for monies from the foundation and HUD for \$29 million, and a guaranteed number of Section 8 Housing Subsidy Certificates. Traditionally, the CMI could not gain access to housing because of cost, nor could they leave institutional care in a planned way. By ensuring access to affordable housing through city and state political institutions, RWJF established a high level of support for each project at the outset. In order to be accepted by RWJF each city applicant had to satisfy five criteria:

(a) to create a central authority to take responsibility for clinical, administrative and fiscal tasks

(b) to develop continuity of care

(c) to finance reform

(d) to provide access to local housing

(e) to generate support services to clients living in their own homes.

\section{The demonstration projects}

From over 80 applications grants were awarded to Austin, Texas; Baltimore, Maryland; Charlotte, North Carolina; Cincinnati, Columbus and Toledo, Ohio; Denver, Colorado; Honolulu and Philadelphia, Pennsylvania. The purpose was to change systems, which necessitated a considerable degree of political support at the outset, including that of a number of national and state-wide agencies.

The RWJF programmes involved independent evaluation by the University of Maryland Medical School Department of Mental Health Policy Studies, under the leadership of Professor Howard Goldman. The foundation required that each project had to show organisationally how it negotiated local political support. Each project also had to identify a set of specific objectives and describe its development and progress over the first three years. For example, the Columbus project, which was established with the support of the local county Mental Health Board, had the objective of establishing a client-centred treatment system delivered by continuous treatment teams. These provide outreach, primary treatment and specialist provision for people with dual diagnoses of functional psychosis and substance abuse. So far five teams of five clinicians (not necessarily medical) have been established, each team providing a service for over 100 people, working from facilities supported by the County Mental Health Board.

Early evidence suggests that for many clients alternatives to hospital admission are achieved and homelessness avoided.

\section{Case management}

The RWJF-funded demonstration projects in contrast to the community mental health movement looked to case management to produce less fragmented services. Each client is allocated a case manager to identify key problems with the client and co-ordinate its agencies involved. Problems are identified using the SHARES format (Symptoms, Housing, Activities of daily living, Recreation, Employment, Significant Others - or primary carers) devised by Stein \& Test (1980) in their work in Wisconsin. Like a key worker, a case manager devises a care plan with a client, but unlike a key worker s/he may not necessarily implement it, having instead the responsibility to ensure that the client receives the services set out in the care plan. Case managers act as advocates and service co-ordinators for their client. The client in turn is much less likely to remain dependent upon an individual who may move on or become ill-a serious flaw in system where a key worker undertakes all the work on a care plan.

Already there are important developments in the area. At the Maudsley Hospital, Connelly is evaluating a service based on the Stein \& Test model and developing a training programme for professionals. As Aiken (1987) has observed, existing training for health professionals to care for people in the community is inadequate, and the case manager may develop into a new generation of community mental health worker. Such changes and development of multi-disciplinary skills sharing would also affect psychiatrists, as the new models of service pose particularly difficult questions as to the relationship between acute services and rehabilitation services. It is essential that health care professionals at local level are able to face and answer these challenging issues.

\section{Implications for UK}

The problems of community care in Britain bear a remarkable similarity to the situation in America, 
although the systems of health care and social services differ. Between 1977 and 1987 the number of hospital residents in the UK fell by $30 \%$ from 84,000 to 60,000 , while at the same time the number of residential places in the community increased by only 4,000 places (Department of Health, 1989). Homelessness has increased dramatically. Ex-patients in jail or who were homeless could not receive a managed service.

Political disagreements between many inner city local authorities and central government have lead to funding crises. In America this conflict was between federal and state government, whereas in Britain it is between central and local government. Both conflicts produce the same result for the consumer-fragmented services. The current fear among those implementing Caring for People is that community care policies are really concerned with reducing central government expenditure. Clearly there are parallels between the fragmentation of services identified by RWJF and in our own system.

The RWJF approach offers a way of working which is an alternative to fragmentation. The starting point is that change is to be welcomed and coordination of effect is a key aspect of service planning and delivery. Such an approach is based on principles, it is not prescriptive, nor driven by any single discipline or ideology. Local cooperation and good practice take the place of single answer solution to complex problems.

The current changes in mental health services are exciting because they are moving away from a sole concern with detained patients to care in patients own communities. The RWJF principles do not have to be restricted to America - the opportunity is here for the taking.

\section{Conclusions}

The RWJF process assumes that if enthusiasts are found, and supported financially and managerially, a new type of service can be developed, which is desirable to clients and providers, and is cost effective. Many of the components identifiable in these projects are also to be found in this country; what is so often missing in Britain is the opportunity to realise this potential. Central to the RWJF approach is the notion that choices should be real for patients and professionals alike. To achieve successful systems change means identifying opinion formers in the community and in the services, and harnessing their energies. Finally, it seems that in Britain it has taken time to learn the lesson that quality of service is not an optional extra, and neither is evaluation of new service provision.

\section{References}

AIKEN, L. H. (1987) Unmet needs for the chronically mentally ill: will nursing respond? IMAGE: Journal of Nursing Scholarship, 19, 121-125.

Department of Health (1989) Personal social services: provision for mentally ill people in England 1977-1987. Statistical Bulletin, 3,89.

Goldman, H., Adams, N. H. \& Taube, C. A. (1983) Deinstitutionalisation: the data demythologised. Hospital and Community Psychiatry, 34, 129-134.

- \& MORRISSEY, J. P. (1985) The alchemy of mental health policy: homelessness and the fourth cycle of reform. American Journal of Public Health, 75, 727-731.

Griffiths, R. (1988) Community Care: An Agenda for Action. London: HMSO.

STEIN, L. A. \& TEST, M. A. (1980) Alternatives to mental hospital treatment. Archives of General Psychiatry, 37, 392-397.

\section{Members fluent in European languages}

The College is focusing increasingly on the development of its links with other European countries and is keen to recruit the help of Members with expertise in European languages. Any Members who are fluent in a European language and who would be prepared to help us communicate with other psychiatric organis- ations are asked to contact me as soon as possible. I envisage that this commitment would be light; probably involving translating some correspondence and occasional scientific papers.

Dr Fiona Caldicott 